\title{
Redes sociais digitais e a comunicação organizacional em uma universidade federal
}

\section{Digital Social Networks and organizational communication at a federal university}

Gabriela Santos Dayrell Ferreira ${ }^{1 *}$, Cinthya Rocha Tameirão ${ }^{1}$, Luciana Pereira de Assis, Altamir Fernandes de Oliveira ${ }^{1}$, João Antônio Gomes Pereira ${ }^{2}$

\begin{abstract}
RESUMO
Este artigo analisa a gestão de redes sociais digitais em universidades federais. É comum observarmos nessas redes a existência de diversos perfis de uma mesma universidade. Em geral, são perfis específicos de setores administrativos ou acadêmicos. Destaca-se que as unidades são agentes comunicacionais e a sua fala reflete na instituição. $O$ artigo visa entender os efeitos da descentralização na comunicação organizacional integrada. Os perfis oficiais da universidade foco de análise foram mapeados e analisados comparativamente, por meio de critérios pré-definidos. Tais critérios foram definidos a partir de ampla pesquisa documental. Os resultados apontam ausência de diretrizes da instituição foco para a gestão de redes sociais; ausência de discussão sobre o papel das redes sociais digitais em âmbito da comunicação organizacional integrada; e, gestão dos perfis realizada de modo mais intuitivo do que organizada e consciente dos propósitos. Este artigo aponta que a descentralização no contexto da universidade é positiva, porém deve ser apoiada por um modelo de gestão alicerçado em três pilares: diretrizes claras, acesso à informação e ações para o desenvolvimento de competências midiáticas para os gestores de mídias digitais.
\end{abstract}

Palavras-chave: Comunicação organizacional; Redes Sociais Digitais; Gestão Universitária;

\begin{abstract}
This article analyzes the management of digital social networks in federal universities. It is common to observe in these networks the existence of different profiles from the same university. In general, they are specific profiles of administrative or academic sectors. It is noteworthy that the units are communication agents, and their speech reflects on the institution. The article aims to understand how the effects of decentralization on integrated organizational communication are concerned. In this study, the official profiles of the university focus were mapped and analyzed comparatively, using pre-defined criteria. These criteria were based on extensive documentary research. The results indicate the absence of guidelines from the focus institution for the management of social networks; absence of discussion about the role of digital social networks in the context of integrated organizational communication; and management of these profiles carried out more intuitively than organized and conscious of the purposes. This article points out that decentralization in the university context is positive, but it must be supported by a management model based on three pillars: clear guidelines, access to information, and the development of media skills for managers.
\end{abstract}

Keywords: Organizational communication; Digital Social Networks; University Management;

\footnotetext{
${ }^{1}$ Universidade Federal dos Vales do Jequitinhonha e Mucuri - UFVJM .

* E-mail: gabriela.santos@ufvjm.edu.br

${ }^{2}$ Universidade Federal do Pampa
} 


\section{INTRODUÇÃO}

Em universidades públicas, a comunicação organizacional deve contribuir para a boa convivência em um ambiente comunitário no qual convivem públicos diferentes com uma diversidade de conhecimentos e pensamentos. Além disso, necessita estabelecer uma efetiva conexão com os públicos externos, como famílias, empresas, governo e a sociedade em geral, dada sua natureza pública (BUONO; FORTEZZA, 2017). Ressaltase que "o mundo acadêmico deve sua vitalidade às relações entre suas partes" (BUONO; FORTEZZA, 2017, p. [706]) e a comunicação é a base para a construção desses relacionamentos (LOCK, 2019).

Nas universidades, as partes que compõem a comunidade acadêmica, ao se relacionarem e comunicarem em nome da organização, seja interna ou externamente, a representam e contribuem para a formação da sua reputação a longo prazo (BUONO; FORTEZZA, 2017). Os membros são agentes comunicacionais (BALDISSERA, 2007), interagindo em um contexto midiatizado em que as relações sociais seguem a lógica das trocas midiáticas.

Por um lado, a amplitude ao acesso à comunicação digital e a disponibilidade de conteúdo resultaram em uma comunicação mais democrática, participativa e transparente (CORRÊA, 2016). Durante a Pandemia Covid-19, diante do isolamento social, as comunicações on-line tornaram-se indispensáveis para as universidades e seus públicos. Por outro lado, enquanto amplia-se o alcance da fala oficial, torna-se mais complexo e difícil o controle das demais falas que podem impactar negativamente a imagem da universidade (SILVA; BALDISSERA, 2019). Uma vez que a ação de comunicar "não é exclusiva das estruturas profissionalizadas de comunicação” (BUENO, 2005, p. 46) torna-se necessário discutir melhores práticas para universidades públicas que ao mesmo tempo preservem a interação entre partes da organização e seus públicos específicos e sejam coerentes e aderentes aos propósitos da comunicação organizacional da instituição.

Diante da difusão das redes sociais digitais, essa discussão é ainda mais relevante. Essas redes ampliaram a sua importância como meio comunicacional para que departamentos, cursos e mesmo unidades administrativas falassem diretamente com seus públicos de interesse, por meio de perfis próprios, ao invés de centralizar a comunicação 
em apenas um perfil institucional. A descentralização permite a comunicação mais direta e com conteúdo de maior interesse para um público específico. Por outro lado, cada perfil representa a Universidade Federal dos Vales do Jequitinhonha e Mucuri (UFVJM) e torna-se parte da comunicação da universidade.

Este artigo aborda a descentralização da gestão das redes sociais digitais, entendendo que são parte da comunicação organizacional. Consideramos a gestão dessas redes o processo que envolve planejamento, produção, publicação de conteúdo, monitoramento e análise dos resultados. $\mathrm{O}$ uso das redes sociais digitais de forma descentralizada por diversas unidades pode ter efeitos para a comunicação organizacional integrada. Um estudo de caso foi realizado na UFVJM, empregando a pesquisa documental e entrevistas para compreensão do fenômeno.

Foram identificados 38 perfis de setores acadêmicos ou administrativos da UFVJM, além dos perfis institucionais, nas redes sociais digitais Facebook e Instagram. Uma análise comparativa baseada em critérios construídos a partir da pesquisa documental evidenciou situações diversas, quanto ao atendimento a esses quesitos. Especialmente, ausência de interação entre os perfis, ou mesmo interação com os perfis oficiais, criando ilhas de comunicação dentro da mesma instituição. Em relação à universidade, não foram identificadas diretrizes voltadas à gestão de redes sociais digitais. Observa-se que os perfis de unidades da universidade não estão integrados à comunicação organizacional.

As universidades públicas têm características que as distinguem de outras organizações, como a autonomia e estrutura de tomada de decisão colegiada, divisão de unidades acadêmicas em faculdades e cursos com abrangência de diferentes áreas de conhecimento e públicos de interesse específicos (SANTOS, 2013). Nesse sentido, a interação e diálogo proporcionado pelas redes sociais digitais deve ser estimulada, até mesmo em virtude da natureza pública da universidade. Contudo, é necessário que se compreenda que essas mídias são parte da comunicação organizacional, o que leva a necessidade de elaboração de diretrizes, melhores práticas e orientação para a gestão de redes sociais digitais.

\section{REDES SOCIAIS DIGITAIS: OPORTUNIDADES E DESAFIOS PARA A COMUNICAÇÃO ORGANIZACIONAL}


Nas relações comunicacionais, os envolvidos são impulsionados por diferentes percepções que, tensionadas, transformam-se em forças variadas e multidirecionais. Essa característica, impossibilita que a comunicação seja totalmente controlada, intencionalmente conduzida, uma vez que é dependente dessas relações, da interação e percepção do outro. A fala oficial da organização é afetada pelo que está fora do sistema formal (BALDISSERA, 2009). Essa dinâmica reflete-se na organização, que é redimensionada delimitando novos contornos a partir "dos seus diálogos, disputas e articulações internas, sofre influências, complexas e dinamicamente, das transações que atualizam com ou/no ambiente”. (BALDISSERA, 2007, p. 236).

Não é possível predeterminar os efeitos da mensagem para o interlocutor (SERRA; CANAVILHAS, 2009), que faz a sua leitura própria. Tais percepções e interações formam a imagem imediata da organização para o indivíduo ou grupo de indivíduos e, com o tempo, consolidam a reputação da organização. Os públicos se identificam com uma organização de acordo com as informações que recebem sobre ela, sejam oficiais ou não. A comunicação organizacional opera nesses limites, devendo nortear a fala da instituição embasado por seus valores e ciente dos valores dos seus públicos. (BALDISSERA, 2007).

$\mathrm{Na}$ sociedade midiatizada os processos interacionais se desenvolvem "segundo lógicas da mídia", onde as relações são permeadas por mídias interativas de base tecnológica e a sociedade é organizada nesse mesmo sentido. (BRAGA, 2006, p. 10). Mesmo em contextos em que as pessoas não estão interagindo através da mídia, seja produzindo ou recebendo a informação, ela provoca influência nas relações em sociedade e em diferentes áreas. (BRAGA, 2006). Na midiatização as relações de tempo, espaço e contextos alteram as formas de se relacionar enquanto indivíduos, organizações e sociedade (FIGUEIRAS, 2017), potencializando a complexidade da comunicação organizacional, sobretudo nas redes sociais digitais. (BALDISSERA; VINHOLA, 2020)

$\mathrm{O}$ espaço interativo das redes sociais digitais possibilita a troca dialógica e alternância dos papéis de emissor e receptor (BALDISSERA; VINHOLA, 2020). As redes sociais digitais democratizaram a fala, configurando-se como espaço aberto a diálogo e interação (MACNAMARA; ZERFASS, 2012). Enquanto para as pessoas, a participação nas redes sociais digitais é fácil e corriqueira, para organizações essa decisão requer ver o espaço como parte de sua comunicação organizacional. Apenas o uso de 
recursos e plataformas digitais de comunicação não garantem que a organização estabeleça uma interação com seus públicos ou que alcance os objetivos comunicacionais (SILVA; BALDISSERA, 2019; WIRTZ; ZIMBRES, 2018).

Estar presente nas redes sociais digitais requer foco nos objetivos que a organização pretende alcançar ao administrar as potencialidades de cada canal de acordo com "os níveis de visibilidade ou opacidade" pretendida pela organização; quais "sentidos e informações" sobre ela são disseminados na web; de que forma e com qual qualidade a imagem da instituição é apresentada aos públicos; como (re)afirmar os seus valores neste ambiente; e como estabelecer melhorias estratégicas através do exercício de ouvir seus interlocutores (SILVA; BALDISSERA, 2019, p. 287).

As organizações "talvez busquem legitimidade social e proximidade de seus públicos" ao ingressar nas redes sociais digitais (SILVA, 2018, p. 80). Contudo, as mídias sociais digitais mais do que meios informacionais, constituem-se espaços dialógicos (SILVA; BALDISSERA, 2019, p. 271). A falta de observação a essa questão pode levar a distanciamento, devido a "sensação de impessoalidade, de desatenção, e até mesmo de descaso com as mensagens que são direcionadas ou que envolvem uma organização" (SILVA, 2012, p. 114). Quando a organização cria um perfil para utilizá-lo apenas de modo informativo e sem disposição para o diálogo, a organização deixa de ter sentido, ou de conquistar o engajamento de seus públicos

Ao optar por criar uma presença digital, o planejamento da comunicação organizacional deve se pautar em uma comunicação integrada. Trata-se de realizar a comunicação de forma estratégica e articulada entre os diferentes canais, amparada por valores organizacionais e diretrizes comunicacionais. Tem-se por objetivo aproveitar as oportunidades que as diferentes mídias digitais possuem, melhorando e potencializando a experiência do público com a organização (BUENO, 2005; SILVA, 2012).

$\mathrm{Na}$ Internet, organizações e públicos dialogam com as mesmas possibilidades de expor seus discursos e opiniões. Os indivíduos podem criar e divulgar informações que são do interesse da organização, tornando um desafio para essas instituições o controle sobre o fluxo e teor das informações no ambiente digital. (THOMPSON, 2008). O que é reverberado não é apenas o que a organização diz sobre si, mas também as interações diretas dos públicos com ela e dito indiretamente sobre ela. (BALDISSERA, 2007; BALDISSERA; VINHOLA, 2020). 
A falta de estratégia para condução das redes sociais digitais, ou o desconhecimento das lógicas comunicacionais nesses espaços podem afetar a imagem organizacional. Conflitos podem acontecer, discursos contraditórios ou complementares, entre organização e seus públicos-alvo, podem coexistir nesses espaços (ROMAN, 2009). Isso torna necessário o compromisso com a transparência na comunicação, coerência entre discurso e prática (SILVA, 2012) e o desenvolvimento de competências midiáticas para gestores dessas redes sociais digitais. Competências compreendidas como a capacidade de relacionar-se criticamente, através de um conjunto de recursos, procedimentos e percepções sobre as tendências de midiatização dos sistemas que os cercam, a fim de desenvolver uma comunicação mais clara, coerente, espontânea e confiável (BALDISSERA; KAUFMANN; SARTOR, 2013, p. 22; BRAGA, 2006).

\section{UNIVERSIDADES FEDERAIS E O COMPROMISSO COM A COMUNICAÇÃO PÚBLICA}

Nas universidades federais a comunidade universitária, por meio de representações em conselhos e comissões, participa da construção de resoluções e normativas que embasam a tomada de decisão e práticas. É previsto que ocorra estímulo à participação das pessoas e a discussão de ideias, onde o gestor atua como condutor das deliberações (CARVALHO, 2013; PAIVA, 2016).

As universidades são instituições que estão em frequente transformação e constante inter-relação com a sociedade, por meio de ensino, da pesquisa e da extensão, sendo parte ativa da comunidade (SILVA, 2012). Uma universidade é constituída por diversos subsistemas, que interagem continuamente e participam das tomadas de decisões colegiadas que caracterizam sua estrutura. Se por um lado, essa divisão pode levar a uma maior participação da comunidade acadêmica na tomada de decisão, por outro lado, pode acarretar a fragmentação da unicidade, com disputas de poder entre unidades e resistência a mudanças (SILVA, 2012).

Todas as estruturas administrativas, unidades acadêmicas e seus setores, dialogam entre si, com os públicos internos e externos e comunicam em nome da instituição, tornando-se seus representantes ao disseminar a identidade da organização e influenciar a sua imagem e a consolidação de sua reputação. (BUONO; FORTEZZA, 2017).

Como autarquias do Governo Federal, as universidades federais possuem compromisso com a comunicação pública, divulgando informações de interesse dos 
cidadãos e promovendo o diálogo entre as partes. A comunicação pública é um termo de múltiplos sentidos, todos eles relacionados à participação e interesse público. Sobre esse aspecto, Duarte (2007, p. 3) esclarece que: “A existência de recursos públicos ou interesse público caracteriza a necessidade de atendimento às exigências da comunicação pública”. Refere-se à responsabilidade do Estado em informar, comunicar e estabelecer um diálogo com o cidadão. Neste sentido, é papel da comunicação pública divulgar informações de interesse público e promover o diálogo para o início da aproximação entre cidadão e Estado (MANIERI; RIBEIRO, 2011).

Além disso, dentre as finalidades da educação superior, está "promover a divulgação de conhecimentos culturais, científicos e técnicos que constituem patrimônio da humanidade e comunicar o saber através do ensino, de publicações ou de outras formas de comunicação" (BRASIL, 1996). Portanto, as instituições científicas precisam estabelecer um espaço público de diálogo com "sujeitos que, de algum modo, a tais instituições se vinculam e por elas sentem-se afetados." (MAFRA, 2016, p. 169). Neste contexto, as redes sociais digitais possibilitam a divulgação abrangente e amplificam a interação em que o cidadão não é apenas consumidor de informação, mas também, produtor e transmissor de conteúdo. (MANIERI; RIBEIRO, 2011).

\section{PROCEDIMENTOS METODOLÓGICOS}

A pesquisa empregou o método de estudo de caso, em uma perspectiva interpretativista, para compreender o processo de gestão das redes sociais digitais como elemento da comunicação organizacional da UFVJM. As técnicas utilizadas foram a pesquisa documental e entrevistas. Esta pesquisa foi aprovada pelo Comitê de Ética em Pesquisa (CEP), da UFVJM.

$\mathrm{Na}$ primeira etapa, foram levantados documentos internos relacionados à comunicação organizacional, como o Manual de Identidade Visual da UFVJM (UFVJM, 2011), resoluções e Planos de Desenvolvimento Institucional (PDI), e outros documentos como legislação federal sobre comunicação digital e as normativas sobre redes sociais digitais, disponibilizadas pela Secretaria Especial de Comunicação Social da Presidência da República (Secom). Esse estudo, somado a revisão teórica, possibilitou definir categorias para análise de perfis das redes sociais digitais e criar um roteiro semiestruturado para as entrevistas. Foram criadas cinco categorias: identidade pública 
federal; acessibilidade e informação; compartilhamento; qualidade das imagens; postagens e interações. Para cada categoria foram definidos indicadores.

$\mathrm{Na}$ etapa seguinte, foram mapeados perfis nas redes sociais digitais Instagram e Facebook de unidades pertencentes à UFVJM que se apresentam como tal. Foram analisados 20 perfis da UFVJM no Facebook e 18 perfis no Instagram. Dentre os perfis analisados, no Facebook, 11 pertencem a setores administrativos e 9 a setores acadêmicos. No Instagram 13 perfis pertencem a setores acadêmicos e 5 a de setores administrativos. A coleta de dados em cada perfil foi feita considerando os últimos três meses de postagens no feed de notícias no corpo da página, desconsiderando o espaço dos stories que é transitório. A coleta de dados ocorreu entre os dias 8 e 11 de março de 2020, antes do isolamento provocado pela pandemia.

Os dados foram coletados de acordo com os indicadores de cada categoria. Cada indicador recebia a resposta: frequentemente, eventualmente e nunca, que traduzia o nível de atendimento a esse indicador. A análise dos dados baseou-se em estatísticas de frequência e técnicas de visualização de informações, que facilita a observação e a compreensão dessas informações através da percepção visual (CARVALHO, 2004).

$\mathrm{Na}$ terceira etapa, foram realizadas as entrevistas semiestruturadas que buscavam compreender as práticas de gestão relacionadas ao planejamento, a produção e publicação de conteúdo, o monitoramento e acompanhamento dos resultados. Os entrevistados foram definidos por critério de acessibilidade e relevância. A análise de conteúdo categorial foi empregada para a interpretação dos dados das entrevistas (BARDIN, 2011) e as categorias foram criadas com base na revisão teórica e nos dados coletados na análise documental.

\section{A UFVJM E A COMUNICAÇÃO DIGITAL}

A UFVJM é uma universidade nova, criada em 2005, porém suas origens remontam a 1953, com a criação da Faculdade de Odontologia de Diamantina (Faod). Atualmente, a universidade possui mais de 80 cursos, mais de 10 mil discentes de graduação e mais de 1.500 de pós-graduação. O quadro atual de servidores conta com 654 técnicos administrativos e 795 professores em cinco campi localizados em quatro cidades do norte e nordeste de Minas Gerais.

Como autarquia do Governo Federal, a universidade deve se pautar pelos princípios da comunicação pública e atentar às normativas relacionadas à comunicação de órgãos do governo. Dentre as normativas analisadas destacamos a Instrução Normativa 
Secom $n^{\circ}$ 8, de 19 de dezembro de 2014, que trata da identidade da comunicação digital das entidades do Poder Executivo Federal. Nela é possível observar uma visão estratégica da comunicação, o respeito ao público como linha condutora do processo de mudança. $\mathrm{O}$ foco é a experiência de uso do cidadão, seu atendimento e acessibilidade, o que vai ao encontro da comunicação pública, com a aproximação entre o Estado e o cidadão, através da disposição em estabelecer um diálogo com informações, prestação de contas, oferta de serviços e notícias que são de interesse dos seus públicos (BRANDÃO, 2006; MANIERI; RIBEIRO, 2011).

De acordo com o Regimento Interno (RI) da Diretoria de Comunicação Social (Dicom), compete à diretoria a gestão do portal da UFVJM e outras mídias on-line decorrente desse, com “descentralização da inserção de conteúdo e atualização constante das informações, bem como de seus derivados" (UFVJM, 2009, p. 4). Apesar das redes sociais digitais serem mídias on-line, o documento não cita os termos como comunicação digital, redes sociais digitais ou mídias sociais digitais. O RI traz um caráter informacional, de via única, focando na assessoria de imprensa como forma de comunicação com os públicos. Dentre as suas finalidades destaca-se "estreitar as relações com o público [...], utilizando a imprensa e a mídia como mediadoras e geradoras de expectativas;” (UFVJM, 2009, p. 2). Não há discussão práticas voltadas a espaços interacionais e dialógicos.

No PDI, a comunicação digital, especificamente a coordenação do portal web e redes sociais digitais oficiais da UFVJM, está relacionada como um dos objetivos da Dicom para os anos de 2017 a 2021. Para isso, foi criada a meta de aumento da visibilidade da universidade nas redes sociais digitais oficiais A ação proposta no documento foi a criação de perfis oficiais da UFVJM em redes sociais digitais, mas nada foi dito em relação aos demais perfis da UFVJM.

As redes sociais oficiais da UFVJM são geridas pela Dicom. Outras redes sociais digitais, de cursos, departamentos ou outras unidades possuem a gestão descentralizada, por parte dos setores interessados. Compete aos setores administrativos ou acadêmicos autonomia e responsabilidade por publicação e atualização dos seus conteúdos, com intuito de "manter as comunidades interna e externa bem informadas sobre as notícias da instituição". (UFVJM, 2009, p. 4). A descentralização e autonomia dos setores em relação ao portal e outras mídias digitais, não explicitadas, não faz referência a diretrizes, manuais 
ou orientações. A pesquisa documental não localizou outras fontes, manuais, normativas ou diretrizes voltadas à gestão de redes sociais digitais da UFVJM ou de suas unidades.

Em pesquisa realizada pela Dicom, com a comunidade interna e externa, apresentada no Planejamento de Comunicação da UFVJM - 2019 a 2023 (UFVJM, 2019a), as mídias sociais digitais e sites de setores da UFVJM ficaram em terceiro lugar dentre treze opções de meios de comunicação mais utilizado pelos públicos para se informar sobre a universidade. Os perfis oficiais da UFVJM no Instagram e Facebook ficaram em sexto e sétimo lugar. A preferência por redes sociais digitais de outros setores antes mesmo dos perfis oficiais reforçam o espaço e relevância de tais mídias sociais descentralizadas. Essa pesquisa foi realizada no final do ano de 2019 e a Pandemia Covid19 ainda não era uma realidade dos brasileiros. Observamos que para diferentes utilidades, em 2020 os meios de comunicação digital tornaram-se prioritários, ganhando relevância para setores e públicos da universidade. Esse panorama deve se manter.

Ainda que as normas em vigor estabeleçam um direcionamento tanto de forma quanto de conteúdo, o fazem de forma geral, voltados a uma diversidade de órgãos e entidades. A UFVJM carece de normas ou orientações para a comunicação interativa em redes sociais digitais. A ausência de diretrizes amplia chances de equívocos que podem afetar a imagem da universidade em um dado momento.

\section{DISCUSSÃO DOS RESULTADOS}

A análise dos 38 perfis, entre Instagram e Facebook, pertencentes às unidades acadêmicas e administrativas, indicou uma variedade de práticas, com atendimento distinto a cada indicador. Em nenhuma categoria todos os indicadores são atendidos de forma satisfatória, como mostra o Quadro 1.

Quadro 1 - Categorias para análise em redes sociais digitais na Internet 


\begin{tabular}{|c|c|c|}
\hline \multirow{5}{*}{$\begin{array}{l}\text { Identidade } \\
\text { Público Federal }\end{array}$} & Identifica na descrição que pertence a setor da UFVJM & $\mathbf{8 9} \%$ \\
\hline & Postagem com identificação do nome UFVJM & $16 \%$ \\
\hline & Marca UFVJM de acordo com o Manual de Identidade Visual & $63 \%$ \\
\hline & Segue perfil de órgão do Governo Federal & $18 \%$ \\
\hline & Segue o perfil oficial da UFVJM & $16 \%$ \\
\hline \multirow{2}{*}{$\begin{array}{l}\text { Acessibilidade e } \\
\text { informação }\end{array}$} & Informações sobre regras de uso do perfil & $0 \%$ \\
\hline & Possui “\#pracegover” & $5 \%$ \\
\hline \multirow[t]{2}{*}{ Compartilhamento } & Compartilha postagens ou marca os perfis da UFVJM Oficial & $11 \%$ \\
\hline & $\begin{array}{l}\text { Compartilha postagens ou marca os perfis de outros órgãos do } \\
\text { Governo Federal }\end{array}$ & $3 \%$ \\
\hline \multirow[t]{3}{*}{ Imagens } & Imagens com qualidade & $100 \%$ \\
\hline & Imagens com legendas & $74 \%$ \\
\hline & Imagens com crédito de autoria & $13 \%$ \\
\hline \multirow{7}{*}{$\begin{array}{l}\text { Postagens e } \\
\text { interações }\end{array}$} & Provoca interação com usuário & $0 \%$ \\
\hline & Responde perguntas dos usuários & $74 \%$ \\
\hline & Postagens no feed com frequência igual ou inferior a um mês & $61 \%$ \\
\hline & Conteúdo institucional & $\mathbf{8 9} \%$ \\
\hline & Linguagem clara e direta & $\mathbf{9 7 \%}$ \\
\hline & Meme ou humor & $0 \%$ \\
\hline & Tagueamento ou marcadores para postagens & $34 \%$ \\
\hline
\end{tabular}

Fonte: Dados da pesquisa.

Os itens mais bem atendidos pelos perfis, que se destacam positivamente na análise dos perfis foram: a) "Identifica no nome do perfil que o setor pertence à UFVJM"; b) "Identifica na descrição que pertence à setor da UFVJM"; c) "imagem com qualidade"; d) "conteúdo institucional"; e) "linguagem clara e direta". Esses itens foram encontrados satisfatoriamente em $97 \%$ dos perfis pesquisados. 
A identificação do setor e do pertencimento à UFVJM é positiva e reforça que o perfil é parte da universidade. Os servidores falam pela universidade e tornam-se Embaixadores da Marca, como denomina Baeda (2014). Assim, a fala e práticas do perfil contribuem para a consolidação da marca da UFVJM perante o público.

O resultado do uso de imagens de qualidade de resolução e relacionadas ao conteúdo também é positivo. O item "linguagem clara, direta e curta" apresentou um bom resultado. $\mathrm{O}$ uso de textos longos e complexos afastam o internauta e possibilita a leitura de "meia informação", situação em que o público lê apenas trechos do que foi postado, acredita ter compreendido o todo e pode fazer uma interpretação equivocada do que a instituição pretendia com a postagem (SECOM, 2014).

Por outro lado, os itens menos frequentes nos perfis pesquisados foram: a) "informações sobre regras de uso"; b) "Possui \#pracegover"; c) "Compartilha postagens ou marca os perfis da UFVJM Oficial"; d) "Compartilha postagens ou marca os perfis de outros órgãos do Governo Federal"; e e) "autoria das fotos postadas". Alguns dos itens são exigências que se encontram nas normativas da Secom, como informações sobre regras de uso, recursos de acessibilidade e autoria de fotos quando não se trata de banco de imagens livres.

Quanto aos indicadores de interação entre os perfis, a ausência dessa interação cria ilhas de comunicação. Além disso, os perfis deixam de aproveitar conteúdos dos perfis oficiais da UFVJM e de outros órgãos do Governo Federal que podem trazer informações relevantes para o público-alvo, diminuído o tempo de trabalho envolvido com a criação de conteúdo. Além disso o compartilhamento é importante para a cooperação e integração entre os perfis governamentais, ajudando na difusão de informações importantes. (SECOM, 2014).

Percebemos através dos dados coletados que há pouca interação e compartilhamento entre os perfis pesquisados e os perfis da UFVJM Oficial e, também, com outros órgãos do Governo Federal nas duas plataformas, Facebook e Instagram. A cooperação e integração entre eles fornecem ao público mais representatividade, mais conteúdo e uma visão ampla da universidade, ao invés de setores isolados que não dialogam com o restante da instituição.

Chama a atenção a completa ausência de regras de uso nos perfis pesquisados. De acordo com a Secom (2014b, p. 73), a delimitação de regras claras se justifica para garantir a "integridade e transparência do processo de moderação". Em relação à 
acessibilidade, apenas os perfis UFVJM Oficial fazem uso da hashtag inclusiva "pra cego ver", com a descrição da imagem para ser "lida" por programas específicos para deficientes visuais. O uso desse tipo de recurso é recomendado pelas normativas da Secom e visam garantir a participação das pessoas com deficiência sensorial. Outro item ausente em 17 perfis no Facebook e 16 no Instagram foi a informação sobre autoria de fotos postadas. De acordo com a Lei de Direitos Autorais (BRASIL, 1998) e Secom (2014b, p. 66), as imagens devem ser publicadas com “os devidos créditos do autor".

\section{A GESTÃO DOS PERFIS}

As entrevistas foram realizadas com gestores de perfil no Instagram ou no Facebook. O roteiro de entrevistas semiestruturado possibilitou a análise de conteúdo categórica. Os entrevistados, responsáveis pela gestão das redes sociais digitais eram servidores docentes e/ ou técnicos administrativos do próprio setor. Não há envolvimento de uma equipe para discussão de uma agenda de postagens em $67 \%$ dos casos, não há um planejamento de conteúdo, as postagens ocorrem mediante necessidade de se publicar uma informação. Essa atividade não é uma das funções estabelecidas formalmente ao servidor. Os servidores possuem outras atribuições e tiram uma parte do tempo quando necessário para fazer postagens. A pouca ênfase no planejamento reforça o uso das redes sociais digitais como espaço informacional, ao invés de interativo.

Sessenta e sete por cento dos entrevistados disseram não conhecer ou não adotar diretrizes do governo, orientações técnicas ou melhores práticas. Isso pode afetar a capacidade de engajar o público de interesse. Dos entrevistados, 67\% não possuem qualificação na área de comunicação, seja por meio de cursos de graduação, treinamentos ou cursos voltados à comunicação digital, ou gestão de redes sociais digitais. Tudo isso reforça o caráter espontâneo da gestão dos perfis.

Esses aspectos contribuem para entender alguns resultados da pesquisa. Primeiro, quando perguntados sobre a satisfação com o retorno, o engajamento do público, as respostas foram muito diversas. As respostas foram de satisfeitos com o engajamento, parcialmente satisfeitos a insatisfeitos, comentando que há pouca interação. Segundo, a inexistência de uma rotina de acompanhamento das interações com o público e de um padrão de respostas, que considere os princípios da comunicação pública e os valores organizacionais. A falta de retorno em um perfil vinculado à universidade, pode gerar 
insatisfação ou percepção equivocada da importância dada pela organização ao seu público.

Os resultados evidenciaram que o uso das redes sociais digitais tem por objetivo principal ampliar a divulgação e a visibilidade. Somente um dos entrevistados mencionou como objetivo ampliar a interação com o público. Cumprem primeiramente o papel de meio de comunicação de massa. A opção por ter um perfil específico da unidade foi associada à falta de canais de comunicação institucionais para a publicização de informações e notícias de interesse do público específico do setor ou departamento. Os perfis oficiais da UFVJM são gerenciados pela Dicom e possuem a linha editorial com foco na comunicação de interesse geral, o atendimento às orientações da Secom. Porém, o prazo para atendimento e o quantitativo de pessoas no setor são fatores limitantes para $\mathrm{o}$ atendimento das demandas de todas as unidades.

Alguns bons resultados foram apontados. Um dos perfis está em primeiro lugar no número de seguidores no país quando se trata do curso ao qual o perfil representa. Através do perfil conseguiram repercussão positiva e convites de instituições governamentais para participar de projetos e divulgar as boas práticas e concorreram a premiações em virtude de trabalhos divulgados. A universidade pode se beneficiar da troca de experiências positivas como a mencionada.

Contudo, a gestão espontânea e o desconhecimento de normativas, seja do Governo Federal na ausência de diretrizes específicas da universidade, impossibilitam a atuação segura diante de eventuais crises. As redes sociais digitais são espaços de troca, onde podem surgir discursos contraditórios (ROMAN, 2009; SILVA, 2012). É fundamental estar preparado para lidar com situações adversas, que possam afetar a imagem da organização, ou até mesmo a reputação a longo prazo. Pelo menos três entrevistados relataram situações que tomaram conhecimento ou situação vivenciada de problemas que demandou envolvimento de outros para resolver e da exclusão de postagens.

\section{CONSIDERAÇÕES FINAIS}

A universidade é um sistema organizacional complexo formado por diversas partes ao mesmo tempo distintas e interdependentes. A necessidade de comunicação das partes com seus públicos específicos e a facilidade para se criar um perfil em redes sociais digitais levou a criação de inúmeros perfis de cursos e unidades da universidade. Esse 
movimento acontece de forma espontânea e não planejada, mediante necessidade dos diferentes setores.

A gestão descentralizada da comunicação em redes sociais digitais possibilita maior dinamismo e foco nas prioridades e interesses da unidade e de seus públicos de interesse. Contudo, a gestão espontânea, ausência de planejamento de conteúdo e de interação em um perfil que "fala" em nome da UFVJM, pode dificultar o alcance dos objetivos comunicacionais ou trazer prejuízos na relação da instituição com os seus públicos (WOLTON apud SILVA, 2018). Observamos diferentes realidades entre os perfis analisados que refletem diferentes percepções, conhecimento sobre mídias digitais e competências comunicacionais entre os gestores. Esse resultado foi corroborado pelas entrevistas que sinalizaram desconhecimento claro dos objetivos pretendidos, inexistência de planejamento, ou agenda de postagens e padrões e rotinas para acompanhamento das interações.

Possíveis tensões entre a comunicação aberta e não controlada das redes sociais digitais e a necessidade de coerência e coesão em relação a comunicação oficial podem ser equilibradas, para isso é necessário abrir espaço para discussão. Os resultados da pesquisa levaram à compreensão da possibilidade de manter a fluidez da comunicação descentralizada e ao mesmo tempo aprimorar as práticas existentes e estabelecer diretrizes que contribuem para mitigar aspectos negativos.

Consideramos três eixos essenciais: elaboração e divulgação de diretrizes para a comunicação digital e suporte a dúvidas; a capacitação para o desenvolvimento de competências midiáticas; suporte institucional e compartilhamento e trocas de experiências que podem contribuir para a difusão de melhores práticas na gestão dos perfis de redes sociais digitais.

Embora existam normas e diretrizes da Secom, quanto à comunicação digital nos órgãos federais, observamos ausência de orientações, diretrizes e manuais internos, que reflitam as especificidades e objetivos da universidade. Orientações mais amplas, considerando o contexto de midiatização, em consonância com os valores organizacionais são necessárias para nortear as interações com distintos públicos e a visibilidade da universidade. Além de mitigar riscos na imagem institucional, especialmente por ter o compromisso de "produzir a informação pública em direção ao interesse público" (MARQUES; MENEZES; MAFRA, 2018, p. 159) O foco não deve ser as técnicas de 
mídia, operacionalização dos instrumentos e normativas engessadas que não coadunam com a diversidade de um sistema organizacional, como é uma universidade.

A presença nas redes sociais digitais não é suficiente para o alcance de visibilidade e interação. É exigido dos responsáveis novas habilidades midiáticas para lidar com as características destes ambientes digitais e dialógicos, próprios do contexto midiatizado. (SILVA, 2012; CORRÊA, 2016; WIRTZ; ZIMBRES, 2018; BRAGA, 2006). As competências midiáticas são essenciais para lidar com o atual cenário midiatizado, com relações atravessadas por meios. Cabe às organizações e seus gestores aprenderem a lidar com essa realidade. A descentralização irá demandar ações para aprendizagem e desenvolvimento das competências necessárias.

Por fim, é necessário melhorar a integração das partes, para que não se mantenham como ilhas comunicacionais. O compartilhamento de experiências, informações e êxitos favorece o desenvolvimento de práticas. Práticas que mais do que definitivas, sejam dinâmicas e adaptáveis às mudanças constantes nesse meio e em sintonia com a comunicação organizacional.

\section{REFERÊNCIAS}

BADEA, Marius. Social Media and Organizational Communication. Procedia-Social and Behavioral Sciences, v. 149, p. 70-75, 2014.

BALDISSERA, Rudimar. Comunicação Organizacional na perspectiva da complexidade. Organicom. São Paulo, v. 6, n. 10-11, p. 115-120, 2009.

BALDISSERA, Rudimar; VINHOLA, Bruno. Midiatização e comunicação organizacional: aproximações tentativas. Animus, v. 19, n. 39, 2020.

BALDISSERA, Rudimar; KAUFMANN, C.; SARTOR, Basilio. Relações públicas, comunicação organizacional e TDCI's: entre a visibilidade e a vulnerabilidade. In: MOREIRA, Elisabeth R.; PONS, Mônica (org.). Relações públicas, tecnologia e públicos. Santa Cruz do Sul, 2013, v.1, p. 10-26.

BARDIN, Laurence. Análise de conteúdo. Tradução de Luiz Antero Reto e Augusto Pinheiro. $1^{a}$. ed. São Paulo: Edições 70, 2011.

BRAGA, José Luis. Sociedade midiatizada. Animus, v. 5, n. 2, jul.-dez. 2006. p. 9 - 35. Disponível em: <

https://periodicos.ufsm.br/index.php/animus/article/viewFile/6693/4050>. Acesso em 15 de dez. 2020.

BRANDÃO, Elizabeth P.. Usos e Significados do Conceito Comunicação Pública. In: IV Encontro dos Núcleos de Pesquisa da Intercom, Núcleo de Pesquisa Relações Públicas e Comunicação Organizacional, [S. I.], p. 1-14, 2006. Disponível em: 
<http://www.portcom.intercom.org.br/pdfs/38942022201012711408495905478367291 786.pdf> Acesso em: 22 dez. 2018.

BUENO. Wilson da Costa. Comunicação empresarial no Brasil: uma leitura crítica. São Paulo: All Print Editora, 2005. 200 p.

BUONO, Veronica Dal; FORTEZZA, Fulvio. Universities' experience with brand. The role of design in managing university communication and branding. The Design Journal, v. 20, n. sup1, p. S705-S720, 2017.

CARVALHO, Roberto F de. Limites, possibilidades e desafios no processo de gestão e participação das IFES/UFT. Revista da Avaliação da Educação Superior, v. 18, n. 2, p. 351-372, 2013.

CORRÊA, Elizabeth Saad. A Comunicação na sociedade digitalizada: desafios para as organizações contemporâneas. In: KUNSCH, Margarida M. K. (Org.). Comunicaçãa organizacional estratégica: aportes conceituais e aplicados. São Paulo: Summus Editorial, 2016. p. [1103-1490]. E-book.

DUARTE, Jorge. Comunicação pública. [S.I], p. 1-7, 2007. Disponível em: < http://www.jforni.jor.br/forni/files/ComP\%C3\%BAblicaJDuartevf.pdf> Acesso em: 11 mai. 2018.

FIGUEIRAS, Rita. Estudos em mediatização: causalidades, centralidades, interdisciplinaridades. Matrizes, v. 11, n. 1, p. 101-126, 2017.

LOCK, Irina. Explicating communicative organization-stakeholder relationships in the digital age: A systematic review and research agenda. Public Relations Review, v. 45, n. 4, p. 101829, 2019.

MACNAMARA, Jim; ZERFASS, Ansgar. Social media communication in organizations: The challenges of balancing openness, strategy, and management. International journal of strategic communication, v. 6, n. 4, p. 287-308, 2012.

MAFRA, Rennan Lanna Martins. Diálogo público, instituições científicas e democracia: reflexões sobre a constituição de uma política de comunicação organizacional.

Intercom, Revista Brasileira de Ciências da Comunicação, v. 39, n. 2, p. 161-174, 2016. Disponível em:

<http://portcom.intercom.org.br/revistas/index.php/revistaintercom/article/view/2441/19 87> Acesso em: 11 mai. 2018.

MARQUES, Ângela Cristina Salgueiro; MENEZES, Daniela Santiago Mendes; MAFRA, Rennan Lanna Martins. Princípio da igualdade. 2018. p 155-182.

PAIVA, Alysson R. Democracia, deliberação e processo decisório no contexto democrático colegiado em uma instituição. Tese de Doutorado. Universidade Federal de Viçosa. 2016. Disponível

em:<http://www.locus.ufv.br/bitstream/handle/123456789/10055/texto\%20completo.pd f?sequence=1>Acesso em: 22 mar. 2019.

ROMAN, Artur Roberto. Organizações: um universo de discursos bem-ditos, mal-ditos e não-ditos. Comunicação organizacional: linguagem, gestão e perspectivas, v. 2, p. 125-157, 2009. 
SANTOS, Boaventura de Sousa. Pela mão de Alice: o social e o político na pósmodernidade. Coimbra: Edições Almedina, 2013. p. [544]. E-book.

SECOM. Secretaria de Comunicação Social da Presidência da República. Manual de orientação para atuação em mídias sociais: Identidade Padrão de comunicação digital do poder Executivo Federal. Dezembro de 2014. 89p.. Disponível em:>

http://www.secom.gov.br/pdfs-da-area-de-orientacoes-gerais/Internet-e-redessociais/secommanualredessociaisout2012_pdf.pdf>. Acesso em 5 de agosto de 2019.

SERRA, Paulo; CANAVILHAS, João. Informação e Persuasão na Web: Relatório de um Projecto. 2009.p. 183

SILVA, Diego Wander Santos da. As mídias sociais no contexto da comunicação digital das universidades brasileiras. Dissertação de Mestrado. Pontifícia Universidade Católica do Rio Grande do Sul, 2012.

SILVA, Diego Wander Santos da. Comunicação organizacional e as estratégias de invisibilidade e de redução/direcionamento da visibilidade nas mídias sociais. 2018.

SILVA, Diego Wander da; BALDISSERA, Rudimar. Comunicação organizacional e gestão das mídias sociais em agências de comunicação digital. Conexão-Comunicação e Cultura, v. 18, n. 35, 2019.

THOMPSON, John B. A nova visibilidade. Matrizes, v. 1, n. 2, p. 15-38, 2008.

WIRTZ, John G.; ZIMBRES, Thais M. A systematic analysis of research applying 'principles of dialogic communication'to organizational websites, blogs, and social media: Implications for theory and practice. Journal of public relations research, $v$. 30, n. 1-2, p. 5-34, 2018. 